\title{
Neurosurgical Management of Intracranial Metastatic Mesothelioma
}

\author{
Harrison J. Westwick, Gerard H. Jansen, Vasco F. Da Silva
}

Can J Neurol Sci. 2013; 40: 878-880

Mesothelioma is a relatively rare tumor arising from the pleura, most notably associated with exposure to asbestos ${ }^{1}$. Typically, mesothelioma is a locally aggressive tumor with a poor outcome in the order of months from the time of diagnosis ${ }^{2}$. Although cases of distant metastases of mesothelioma have been documented in the literature, this tumor has less reported cases of metastases than other malignancies of the chest, and most reported cases of metastases have been identified in autopsy studies, likely related to the short survival times of patients harboring these tumors.

Brain metastases of mesothelioma are particularly uncommon, with approximately 100 cases documented ${ }^{3}$. Most commonly brain metastases have been discovered in autopsy studies of patients with mesothelioma, but in a small percentage of cases, the diagnosis was made before death.
We have identified only seven reported cases in the literature where neurosurgical intervention was undertaken to manage symptomatic intracranial metastases of mesothelioma, with previous cases tabulated by Winfree and colleagues ${ }^{3}$. Only three previous cases reported surgical intervention for metastatic mesothelioma in the posterior fossa ${ }^{3,4}$. In these seven reported cases, only one was found to have a post-resection survival time of more than three months.

We present this case because of its rarity in neurosurgical pathology. Intracranial metastatic mesothelioma must be entertained as a possible site of tumor metastases in the case of a patient with known mesothelioma. We also report this case to indicate the role of neurosurgical management in the management of a symptomatic patient with intracranial metastatic mesothelioma.
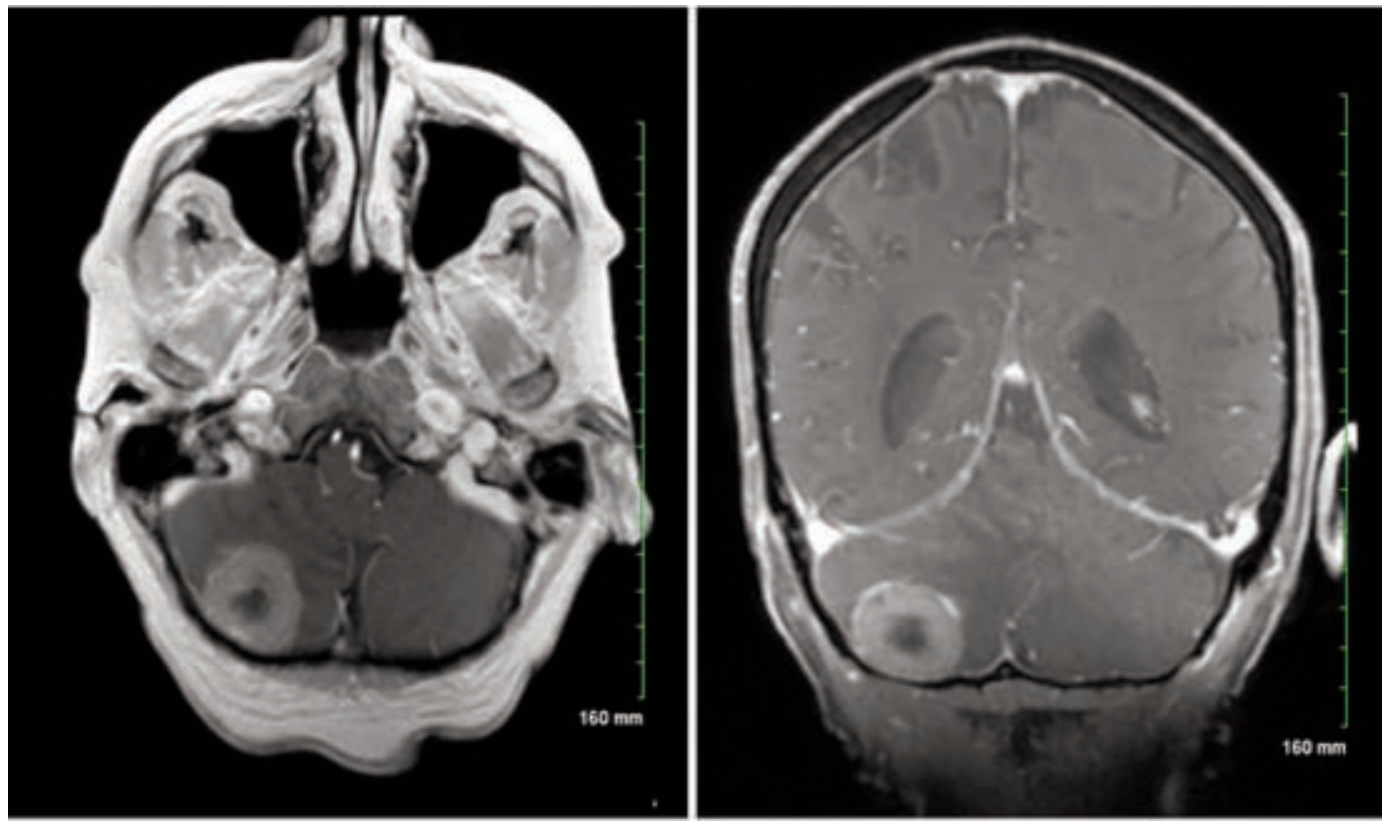

Figure 1: A) Axial, and B) coronal T1 weighted MR images with gadolinium identifying the enhancing $2 \mathrm{~cm}$ mass in the posterior fossa.

From the Faculty of Medicine (HJW, GHJ, VFDS), University of Ottawa; Division of Pathology and Laboratory Medicine (GHJ), Division of Neurosurgery (VFDS), The Ottawa Hospital, Ottawa, Ontario, Canada.

Received June 11, 2013. Final Revisions Submitted July 4, 2013.

Correspondence to: Vasco F. Da Silva, The Ottawa Hospital, C2 - 1053 Carling Ave, Ottawa, Ontario, K1Y 4E9, Canada. Email: vdasilva@ottawahospital.on.ca. 


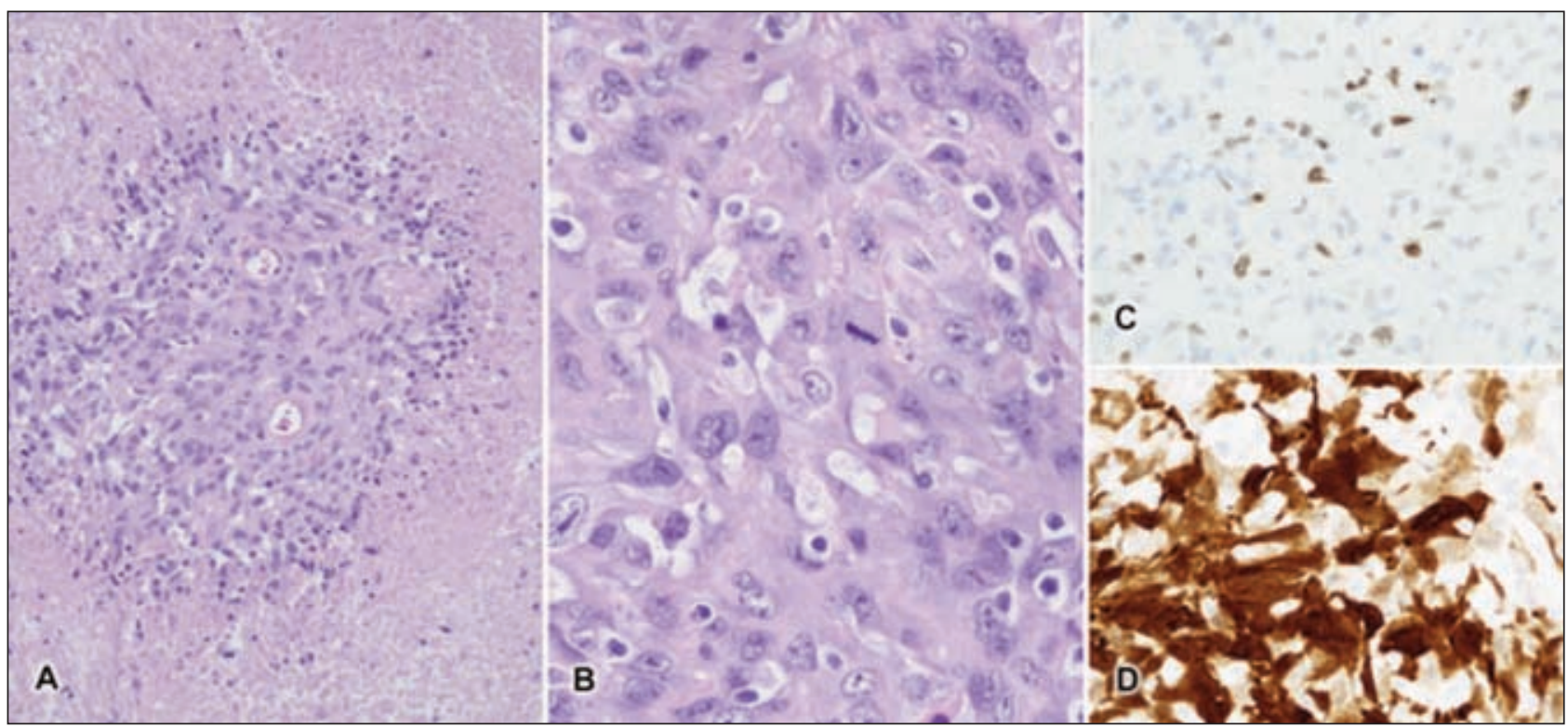

Figure 2: Hematoxylin and eosin $(H \& E)$ pathological sections of the resected tumor specimen $(A)$ demonstrating a poorly differentiated tumor with central necrosis, $(B)$ demonstrating brisk mitotic activity, $(C)$ positive WT1 immunohistochemistry, and (D) positive calretinin .

\section{CASE REPORT}

A 75-year-old male patient with a one year history of right pleural mesothelioma presented to hospital with a three week history of occipital headaches and in an unsteady gait. He had previously been treated with six cycles of Carboplatin and Pemetrexed. His medical history was otherwise complicated by prostate cancer, diverticulitis, type 2 diabetes, hypertension, cholelithiases, and hiatus hernia. On physical examination in the emergency department, the patient had a Glasgow Coma Scale (GCS) of 15 with a normal neurological examination.

He was admitted to hospital with a computed tomography (CT) scan demonstrating a cerebellar mass with vasogenic edema without evidence of hydrocephalus. Magnetic resonance imaging (MRI) showed an intra-axial lesion in the right cerebellar hemisphere with heterogeneous peripheral enhancement and extensive vasogenic edema (Figure 1). There was also a smaller, enhancing lesion in the left temporal lobe which was consistent with a second metastasis.

The patient was taken to the operating room with a provisional diagnosis of a metastatic brain tumor in the posterior fossa. Briefly, he was placed in the left lateral decubitous position, and with the assistance of neuronavigation, the tumor was resected using microsurgical techniques. The patient recovered satisfactorily with no residual deficits.

The surgical specimen was described as a single spherical nodule with an irregular bosselated surface measuring $1.5 \mathrm{~cm}$. At cut surface it revealed a fairly homogenous surface with a necrotic and hemorrhagic centre. At microscopy it showed neoplastic tissue invading the cerebellar folia. The tumor was composed for the most part of sheets of eosinophilic epithelioid cells with poorly delineated cytoplasm and oval nuclei with frequent nucleoli and brisk mitotic activity. Large and irregular areas of necrosis were identified. A few areas with more fascicular oriented elongated tumor cells were found. Glandular growth pattern or myxoid matrix were not identified in the tumor tissue. Immunohistochemistry was positive for calretinin, epithelial membrane antigen, vimentin, Wilm's tumor gene product 1, low molecular weight keratin $\mathrm{AE} 1 / 3$, and keratin $8 / 18$. There was a $70 \%$ proliferation rate in the KI-67 marker. Immunohistochemistry was negative for TTF-1, keratin 5, CEA, and Ber-EP-4, eliminating the possibility of a pseudomesotheliomatous adenocarcinoma. The tumor was identified as a metastatic mesothelioma of mainly epithelioid subtype (Figure 2A-D).

The patient was discharged from the hospital, in satisfactory condition, six days after the surgical resection with referral to the radiation therapy service. He was seen in clinic six weeks post surgery showing resolution of his neurological symptoms.

\section{DISCUSSION}

Although this case is not the first documented case of intracranial metastatic mesothelioma, it is a rare case presentation highlighting the metastatic potential of mesothelioma to the brain and the potential surgical management of this condition. Only very few patients have been diagnosed with neurological manifestations of mesothelioma metastatic to brain, with one recent report citing as few as seven documented cases in living patients ${ }^{2}$. In our review of the literature, we identified less than 20 cases of patients with symptomatic metastatic mesothelioma. The previous cases with neurosurgical management are grouped in the Table ${ }^{2-5}$. It was previously believed that mesothelioma was a process limited mostly to the thoracic cavity but, in recent autopsy case series, it was found that up to $50 \%$ of patients with mesothelioma had some type of distant metastases. In a post-mortem analysis of 318 patients with mesothelioma, analyzing a multicentre 
Table: Tabulated literature review of cases

\begin{tabular}{|c|c|c|c|c|c|c|c|}
\hline Author & Year & $\begin{array}{l}\text { Age/ } \\
\text { Sex }\end{array}$ & Location & Size & Clinical & Neurosurgical Intervention & Outcome \\
\hline Present Case & 2012 & $75 \mathrm{M}$ & $\mathrm{R}$ cerebellum & $2 \mathrm{~cm}$ & Occipital headaches, gait unsteadiness & $\begin{array}{c}\begin{array}{c}\text { Posterior fossa Craniotomy and } \\
\text { excision of tumor }\end{array} \\
\end{array}$ & \\
\hline Muljono A(5) & 2008 & $67 \mathrm{M}$ & $\begin{array}{l}\text { R Choroid } \\
\text { Plexus }\end{array}$ & $4 \mathrm{~cm}$ & $\begin{array}{l}\text { Dizziness, L Hemianopia, and H/A. Lung } \\
\text { biopsy } 3 \text { months prior }\end{array}$ & $\begin{array}{c}\begin{array}{c}\text { Stereotaxic right temporoparietal } \\
\text { craniotomy }\end{array} \\
\end{array}$ & Died 3 months post-resection \\
\hline Hortobágyi T(4) & 2008 & $71 \mathrm{M}$ & $\begin{array}{l}\text { L Temporal lobe } \\
\text { and R Cerebellar } \\
\text { Hemisphere }\end{array}$ & $4 \mathrm{~cm}$ & $\begin{array}{c}1 \text { month progressive H/A. Excision of } \\
\text { pleural tumor } 2 \text { years prior. No Known } \\
\text { asbestos exposure }\end{array}$ & $\begin{array}{c}\text { Craniotomy and Cerebellar } \\
\text { debulking }\end{array}$ & NS \\
\hline Winfree CJ (3) & 2004 & $71 \mathrm{~F}$ & Cerebellum & $1 \mathrm{~cm}$ & $\begin{array}{l}\text { Neurologically unsymptomatic. } \\
\text { Discovered on metastatic workup }\end{array}$ & \begin{tabular}{|c|}
$\begin{array}{c}\text { Sub-occipital decompression and } \\
\text { excision of tumor }\end{array}$ \\
\end{tabular} & $\begin{array}{l}\text { Died } 8 \text { months after resection } \\
\text { due to cardiopulmonary }\end{array}$ \\
\hline Mah E(2) & 2004 & $67 \mathrm{M}$ & $\begin{array}{l}2 \text { lesions in } \mathrm{L} \\
\text { occipital lobe }\end{array}$ & NS & $\begin{array}{l}\mathrm{R} \text { homonymous inferior quadrantanopia. } \\
\text { SOB and thorocotomy, } 10 \text { months prior. } \mathrm{R} \\
\text { honominous quadrantanopia }\end{array}$ & $\begin{array}{l}\text { Stereotaxic L occipital } \\
\text { craniotomy }\end{array}$ & Well $3 \mathrm{mo} \mathrm{F} / \mathrm{U}$ \\
\hline Wronski M(3) & 1993 & $52 \mathrm{M}$ & L Temporal lobe & NS & Gerstmann syndrome & $\begin{array}{l}\text { Temporal craniotomy and } \\
\text { resection of tumor }\end{array}$ & $\begin{array}{c}\text { Died } 1 \text { wk post craniotomy due } \\
\text { to cardiac compromise }\end{array}$ \\
\hline Huncharek M(3) & 1990 & $\begin{array}{c}\mathrm{NS} \\
\mathrm{M}\end{array}$ & $\begin{array}{c}\text { L Frontal and } \mathrm{R} \\
\text { paracervical } \\
\text { mass } \\
\end{array}$ & NS & $\begin{array}{l}\text { Horner's syndrome and increasing } \\
\text { confusion }\end{array}$ & Biopsy of paracervical mass & $\begin{array}{c}\text { Died months after presentation } \\
\text { of neurological symptoms }\end{array}$ \\
\hline Asoh Y(3) & 1990 & $50 \mathrm{~F}$ & $\begin{array}{l}\text { R Cerebellar } \\
\text { hemisphere }\end{array}$ & NS & N/V, Cerebellar ataxia & Craniotomy and excision of mass & $\begin{array}{c}\text { Died of heart failure related to } \\
\text { intrathoracic manifestations of } \\
\text { mesothelioma }\end{array}$ \\
\hline
\end{tabular}

Tabulated literature review of cases of intracranial metastatic mesothelioma with clinical presentation of the patient, the location and size of the metastases, and the surgical intervention undertaken. NS = not specified.

database, $3 \%$ of patients were identified with brain metastases ${ }^{1}$. Fifty five percent of patients with mesothelioma were identified to have extra-thoracic extension of their tumor. The liver, spleen, and thyroid were the most common sites, with the brain being the fourth. Spread of metastases is typically believed to be hematogenous or lymphatic ${ }^{1}$. Different management strategies had been proposed in the management of symptomatic patients with brain involvement, including chemotherapy alone. In most reported cases, however, symptomatic management or expectant management were the strategies employed.

A variety of different neurological symptoms were identified; however, new onset of confusion was a recurrent feature prompting further investigation for a possible intracranial lesion. There was no clear trend in the intracranial localization of the lesion in the different reported cases. In the series of patients undergoing neurosurgical management of the tumor, only three other patients had their lesion identified in the posterior fossa $\mathrm{a}^{3,4}$.

Given the very few numbers of reported cases, it is difficult to identify with any certainty the projected outcome in patients with intracranial metastases of mesothelioma. In all but one of the seven previous cases, survival was less than three months after the onset of neurological symptoms. The majority of the mortality associated with these cases was from the intrathoracic component of the disease and not from the cerebral metastases 3,4 .

\section{CONCLUSION}

Intracranial metastasis of malignant mesothelioma is a rare event with few documented attempts at surgical management. This case documents a successful resection of a metastatic mesothelioma of the cerebellum, allowing for the patient to return home with symptomatic resolution, and highlights the metastatic potential of mesothelioma to the brain.

\section{REFERENCES}

1. Finn R, Brims F, Gandhi A, et al. Postmortem findings of malignant pleural mesothelioma: A two-centre study of 318 patients. Chest. 2012;142(5):1267-73

2. Mah E, Bittar RG, Davis GA. Cerebral metastases in malignant mesothelioma: case report and literature review. J Clin Neurosci. 2004;11(8):917-18.

3. Winfree CJ, Mack WJ, Sisti MB. Solitary cerebellar metastasis of malignant pleural mesothelioma: case report. Surg Neurol. 2004; 61(2):174-8; discussion 8-9.

4. Hortobagyi T, Thomas NW, King A. 71-year-old man with multiple metastases to the brain. Malignant mesothelioma with cerebellar metastasis. Neuropathology. 2008;28(1):103-5.

5. Muljono A, Ng T, McMaster J, Dexter M. Choroid plexus metastases from pleural sarcomatoid mesothelioma. Pathology. 2008;40(5):530-2. 